\title{
Ultra-Sound Guided Caudal Epidural Blockade Analgesia in Comparison to Paravertebral Blockade for Lower Abdominal Operative Interventions among Children
}

\author{
Sabri A Soltan ${ }^{1 *}$, Hesham S Abdelraouf ${ }^{1}$ and Mahmoud M Alsagheir ${ }^{2}$ \\ ${ }^{1}$ Department of Anesthesia, Faculty of Medicine, Al Azhar University, Egypt
}

${ }^{2}$ Department of Anaesthesia, Faculty of Medicine, Al Azhar University, Assiut, Egypt

*Corresponding author: Sabri A Soltan, MD, Department of Anesthesia, Faculty of Medicine, Al Azhar University, Egypt

\begin{abstract}
Background: Adequate analgesia post-operative is crucial to permit early mobilization and effective cough in order to decrease the respiratory system issues and complications. The usage of peripheral nerve blockage in conjunction with sonographic technology and neural stimulators have resulted in better fascial planes identification.

Aim: To compare the analgesic effectiveness of sonographic -guided caudal epidural blockage versus sonographic -guided single-shot thoraco-lumber paravertebral blockage in pediatric cases undergoing lower abdominal surgeries such as herniotomy.

Methodology: This is a prospective randomized interventional clinical research trial performed in Department of Anesthesiology, Samir Abbas Hospital 'Saudi Arabia to compare single-shot caudal Blockage to single-shot paravertebral blockage conducted on sixty pediatric cases. Categorized randomly into two equal numbered research groups: research Group C (caudal Blockade) and research Group P (paravertebral blockade).

Results: Comparative statistical analysis of research group C (Caudal blockage research group) and research group P (paravertebral blockage research group) as regards Postoperative FLACC ( Face, Legs, Activity, Cry, Consolability) scoring level in which there was no statistical significant difference between both research groups at $0,0.5,1,2$, scoring levels $p$ values $=0.605$, $0.192,0.076,0.130$ consecutively) whereas there was statistical significant higher scoring levels among research group $C$ study subjects in comparison to research group $\mathrm{p}$ study subjects at $3^{\text {rd }}, 6^{\text {th }}, 12^{\text {th }}$ and $24^{\text {th }}$ hours. $(\mathrm{p}$ values $=0.031,0.002,0.000,0.000$ consecutively).
\end{abstract}

Conclusion: analgesia after Sonographic-guided paravertebral blockade administering (bupivacaine $0.25 \% 1 \mathrm{mg} / \mathrm{kg}$ ) is superior in analgesic effects in comparison to sonographic guided mode of caudal epidural blockade.

\section{Introduction}

Lower abdominal surgical interventions are one of the most frequent, procedures practiced in pediatric groups of patients that are linked to considerable amount of post-operative pain. Adequate analgesia post-operative is crucial to permit early mobilization and effective cough in order to decrease the respiratory system issues and complications that could increase morbidity in those categories of cases [1,2]. Caudal epidural block in surgical practice on lower abdominal regions within pediatric patients, using a specific landmark technique, stays the most frequently regional mode of anesthesia practiced. sonographic technology usage has enhanced considerably the proper and correct blockage maneuver positioning $[3,4]$.
The usage of peripheral nerve blockage in conjunction with sonographic technology and neural stimulators have resulted in better fascial planes identification $[5,6]$.

Paravertebral blockage main privilege in usage for analgesia management post-operative is adequate localized pain management besides the capability and capacity to prevent administration of local anesthetic agents in large volumes that could be toxic $[7,8]$. Sonographic guidance Permits proper anatomic visualization in a precise manner that, provides the capability to visualize the local anesthetic agent spread manner during performing the injection, and observes abnormal anatomical relations that is considered a frequent anesthetic clinical scenario $[9,10]$. 


\section{Aim of the Work}

To compare the analgesic effectiveness of sonographic-guided caudal epidural blockage using sonographic -guided single-shot paravertebral blockage in pediatric cases undergoing lower abdominal surgeries such as herniotomy.

\section{Methodology}

This prospective randomized interventional clinical research trial performed in Department of Anesthesiology, Samir Abbas Hospital 'Saudi Arabia to compare single-shot caudal Blockade to single-shot paravertebral blockade conducted on sixty pediatric cases having an age range 4-9 years old, having an ASA scoring I/II scheduled for lower abdominal surgeries such as herniotomy and oricopexy categorized randomly into two equal numbered research groups: research Group C (caudal Blockade ) and research Group P (paravertebral blockade). Exclusive research criteria involved regional analgesic Procedures contraindications e.g. neurological/ cardiac illnesses, spinal or thoracic wall anatomical deformities, growth developmental delays issues, past clinical history of drugs hypersensitivity implemented in the research study. All research study subjects have been clinically followed up post-operatively for 24 hours, by the anesthesiologist. The primary research outcome was the time to first time analgesia was needed within the $24 \mathrm{~h}$ follow-up period. The secondary research outcomes were the time required to conduct the blockade procedures, FLACC scoring levels within one day post-operative time interval.

Cases recruited for the research have been induced inhalationally (using sevoflurane $4-8 \%$ ) then fentanyl $1 \mu \mathrm{g} / \mathrm{kg}$ and atracurium $0.5 \mathrm{mg} / \mathrm{kg}$. Airway have been secured using a suitable endotracheal tube size. consequently, anesthesia has been maintained using $\mathrm{O}_{2} /$ air $\left(\mathrm{FiO}_{2} 0.6\right)$ and sevoflurane. The baseline hemodynamic indices were recorded, and the cases have been properly positioned for each caudal blockage or paravertebral blockage conducted. Hemodynamic indices and the fentanyl boluses numbers have been recorded. After the extubation all study subjects were hemodynamic indices and FLACC scoring levels have been recorded at $0,1 / 2,1^{\text {st }}, 2^{\text {nd }}, 3^{\text {rd }}, 6^{\text {th }}, 12^{\text {th }}$ and $24^{\text {th }}$ hours. Sonographicguided blockade interventions the blocks were administered by an ultra-sound probe with high frequency 10-12 MHz to achieve postoperative analgesia.

\section{Caudal Blockage}

Research study subjects categorized in research group $C$ have undertaken the lateral decubitus position for Sonographic-guided caudal blockage. After sterilization of skin and toweling, a high frequency sonographic transducer positioned transversely over the sacral cornu to obtain the 'frog-eye' sonographic appearance consequently the probe was positioned longitudinally to reveal the sonographic sagittal anatomic view characteristic for the caudal space. By means of a $5 \mathrm{~cm}, 22 \mathrm{G}$ needle, caudal blockage was administered using a $1 \mathrm{mg} / \mathrm{kg}$ of $0.25 \%$ bupivacaine, implementing the in-plane approach.

\section{Caudal Space Anesthetic Anatomy}

Caudal blockage injection of agent is via the sacral hiatus, that is described as an arch shaped opening within the dorsal sacral surface. The sacral canal is continuous with the lumbar spinal canal, and containing the cauda equinal nerve roots, meninges, fat and venous plexus [11].

\section{Anatomic Landmarks}

The sacral hiatus is located below the fourth (or third) sacral spinous tubercles. An equilateral triangle is described with the two posterior superior iliac spines forming the base and the sacral hiatus at the apex. The two sacral cornua could be palpated flanking the rostral margin of the sacral hiatus. The sacral canal is roofed by the sacrococcygeal ligament, a continuation of the ligamentum flavum [11] (Figure 1).

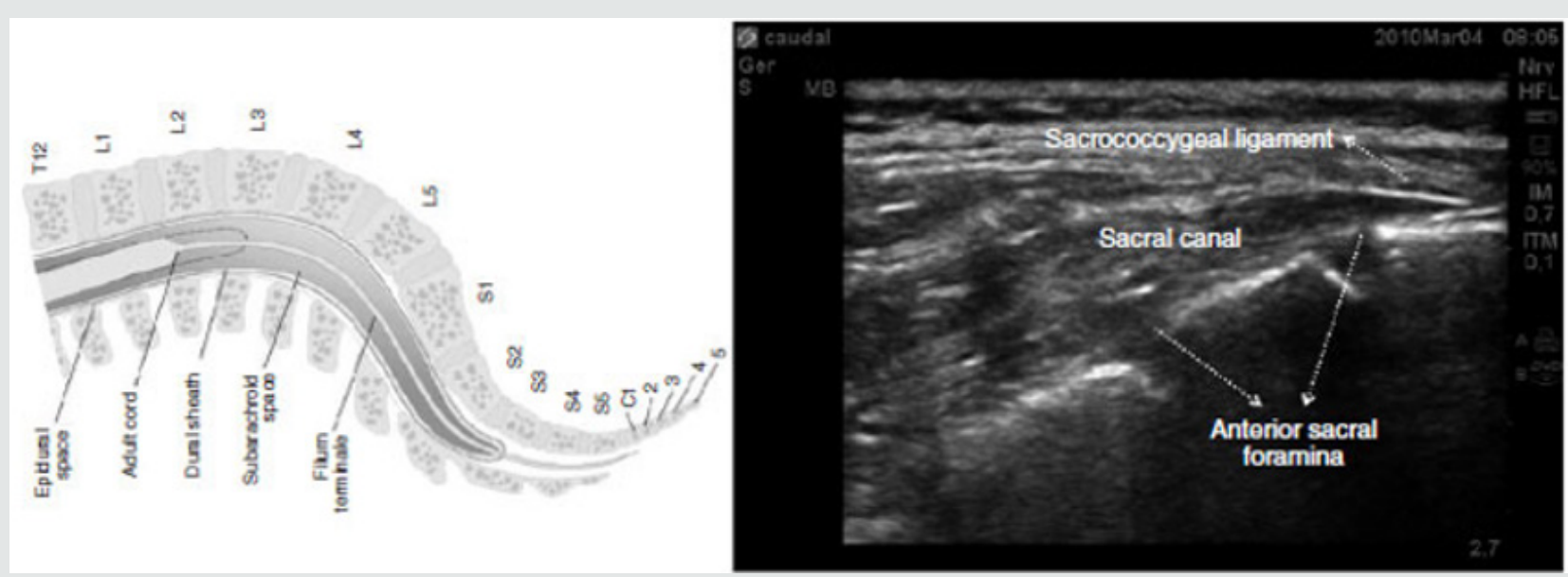

Figure 1: Anatomical comparison of the structures of the lumbosacral region and the longitudinal ultrasound image. 


\section{Paravertebral Blockage}

Cases in research group $\mathrm{P}$ were positioned lateral decubitus position for Sonographic -guided paravertebral blockage at $\mathrm{T}_{11}$ level. After sterilization of skin and draping, a high-frequency sonographic linear probe has been positioned longitudinally to visualize and observed the $\mathrm{T}_{10}-\mathrm{T}_{11}$ spinous processes. The sonographic probe have been consequently positioned laterally till the consecutive transverse processes and matching paravertebral spaces are observed and visualized then the sonographic probe have been positioned in an oblique manner and implementing an in-plane protocol, $1 \mathrm{mg} / \mathrm{kg}$ of $0.25 \%$ bupivacaine have been injected at the paravertebral $\mathrm{T}_{11}$ anatomical space using needle 19 G measurement.

\section{Lumbar Paravertebral Space Anesthetic Anatomy}

Space is bordered anterolaterally by the psoas major muscle, medially by the vertebral bodies, intervertebral discs, and intervertebral foramen with its contents; and posteriorly by the transverse process and the ligaments that are interposed between the adjoining transverse processes [12]. The psoas major muscle is composed of a fleshy anterior part that forms the main bulk of the muscle, and a thin accessory posterior part. The main bulk originates from the anterolateral surface of the vertebral bodies and the accessory part originates from the anterior surface of the transverse process. The two-parts fuse forming the psoas major muscle except near the vertebral bodies where the two parts are separated by a thin fascia in which the lumbar spinal nerve roots and the ascending lumbar veins lie.

The ventral rami of the lumbar spinal nerve roots extend laterally in this intramuscular plane formed by the two parts of the psoas major muscle and form the lumbar plexus within the substance of the psoas major muscle. The local anesthetic agent is injected anterior to the transverse process into a triangular space between the two parts of the psoas major muscle containing the lumbar spinal nerve root [12]. A chain of tendinous arches exists across the constricted parts of the lumbar vertebral bodies, that are traversed by the lumbar arteries and veins and sympathetic fibers. Those tendinous arches could provide a pathway for the spread of local anesthetic agent from the lumbar paravertebral space to the anterolateral surface of the vertebral body [12].

\section{Anesthetic Blockage Mechanism of Paravertebral Space}

A lumbar paravertebral injection triggers ipsilateral dermatomal anesthesia by a direct impact of the local anesthetic agent on the lumbar spinal nerves and by medial extension into the epidural space via the intervertebral foramen [12] (Figure 2).

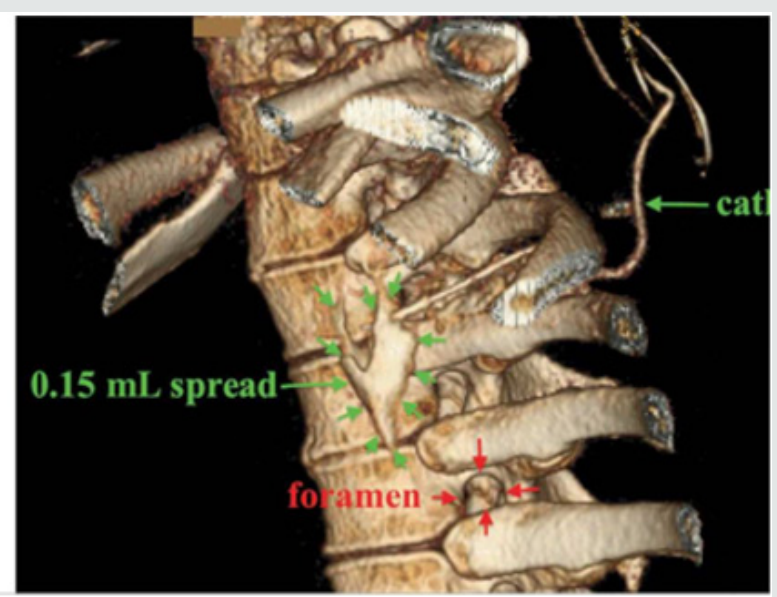

Figure 2: Anesthetic Blockage mechanism of paravertebral space.

\section{Statistical Analysis}

Data were collected, revised, coded and entered to the Statistical Package for Social Science version 23 (IBM SPSS Ver. 23). Qualitative data were presented as numbers and percentages and compared between groups using Chi-square test and/or Fisher exact test only when the expected count in any cell found less than 5. Also, quantitative data were presented as means and standard deviations when parametric and compared using Independent t-test and median with inter-quartile range (IQR) when nonparametric and compared using Mann-Whitney test. The confidence interval was set to $95 \%$ and the margin of error accepted was set to $5 \%$. So, the p-value was considered significant at the level of $<0.05$.

\section{Results}

Table 1 reveals and displays the comparative statistical analysis of research group C (Caudal blockage research group) and research group P (paravertebral blockage research group) as regards demographic research data in which there was no statistical significant difference as regards the age, weight, sex, ASA scoring level, duration of surgery $(\mathrm{min})(\mathrm{p}$ values $=0.636,0.766,0.598$, $0.717,0.374$ consecutively) however the time to administer the blockage was statistically significantly lower among the research group C in comparison to research group $\mathrm{P}(\mathrm{p}$ value $<0.001)$. 
Table 1: Comparison between the two studied groups regarding demographic data $(\bullet$ : Independent t-test *: Chi-square test).

\begin{tabular}{|c|c|c|c|c|c|}
\hline & Group C No. $=30$ & Group P No. $=30$ & Test Value & P-Value & Sig \\
\hline Age (years) & $6.23 \pm 1.85$ & $5.97 \pm 2.36$ & $0.475 \bullet$ & 0.636 & NS \\
\hline Weight (kg) & $16.92 \pm 6.27$ & $17.39 \pm 5.87$ & $0.300 \bullet$ & 0.766 & NS \\
\hline \multicolumn{6}{|c|}{ Sex } \\
\hline Male & $17(56.7 \%)$ & $19(63.3 \%)$ & $0.278^{*}$ & 0.598 & NS \\
\hline Female & $13(43.3 \%)$ & $11(36.7 \%)$ & & & \\
\hline \multicolumn{6}{|c|}{ ASA } \\
\hline I & $25(83.3 \%)$ & $26(86.7 \%)$ & $0.131^{*}$ & 0.717 & NS \\
\hline II & $5(16.7 \%)$ & $4(13.3 \%)$ & & & \\
\hline Time to give the block (sec) & $117.64 \pm 59.46$ & $295.81 \pm 183.52$ & $5.059 \bullet$ & $<0.001$ & HS \\
\hline Duration of surgery (min) & $103.54 \pm 26.4$ & $97.63 \pm 24.67$ & $0.896 \bullet$ & 0.374 & NS \\
\hline
\end{tabular}

Table 2 and Figure 3 reveals and displays the comparative statistical analysis of research group C (Caudal blockage research group) and research group $\mathrm{P}$ (paravertebral blockage research group) as regards Intra-operative heart rate (beat/min) in which there was no statistically significant difference. Table 3 and Figure 4 reveals and displays the comparative statistical analysis of research group C (Caudal blockage research group) and research group P (paravertebral blockage research group) as regards Intraoperative mean arterial blood pressure $(\mathrm{mmHg})$ in which there was no statistically significant difference. Table 4 and Figure 5 reveals and displays the comparative statistical analysis of research group C (Caudal blockage research group) and research group $\mathrm{P}$ (paravertebral blockage research group) as regards number of fentanyl boluses requirement intra-operative in which there was no statistically significant difference ( $p$ value $=0.778$ ) Table 4 and
Figure 6 reveals and displays the comparative statistical analysis of research group C (Caudal blockage research group) and research group P (paravertebral blockage research group) as regards Postoperative FLACC scoring level in which there was no statistical significant difference between both research groups at 0,0.5,1,2, scoring levels $p$ values $=0.605,0.192,0.076,0.130$ consecutively ) whereas there was statistical significant higher scoring levels among research group C study subjects in comparison to research group $\mathrm{p}$ study subjects at $3^{\text {rd }}, 6^{\text {th }}, 12^{\text {th }}$ and $24^{\text {th }}$ hours. ( $p$ values $=0.031,0.002,0.000,0.000$ consecutively). Table 5 and Figure 7 reveal and display that parental satisfaction scores were statistically significantly higher among research $\mathrm{C}$ than research group P (p value=0.033). Table 6 Parental satisfaction scoring among research groups.

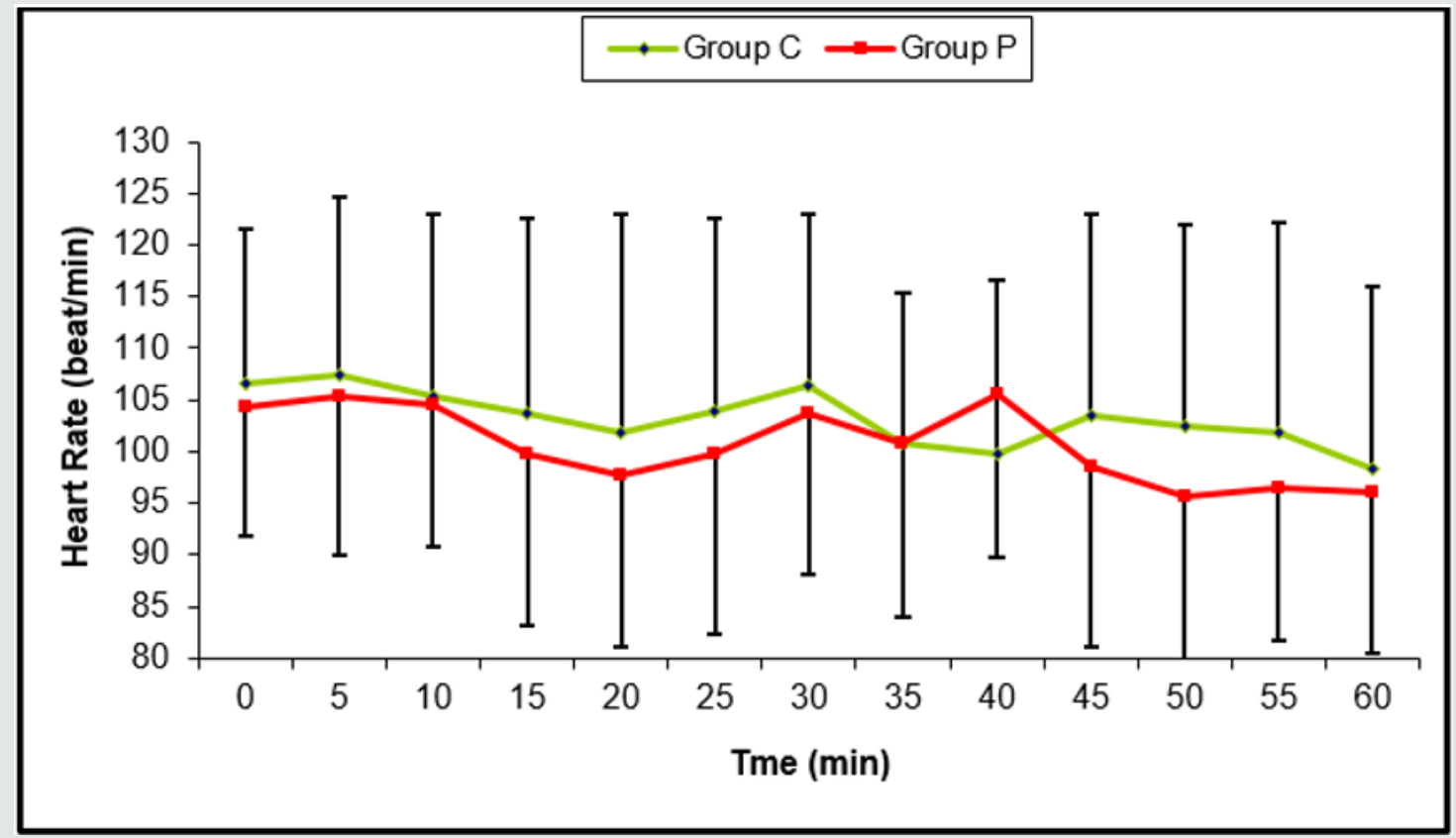

Figure 3: Intra-operative heart rate (beat/min) of the two studied groups. 


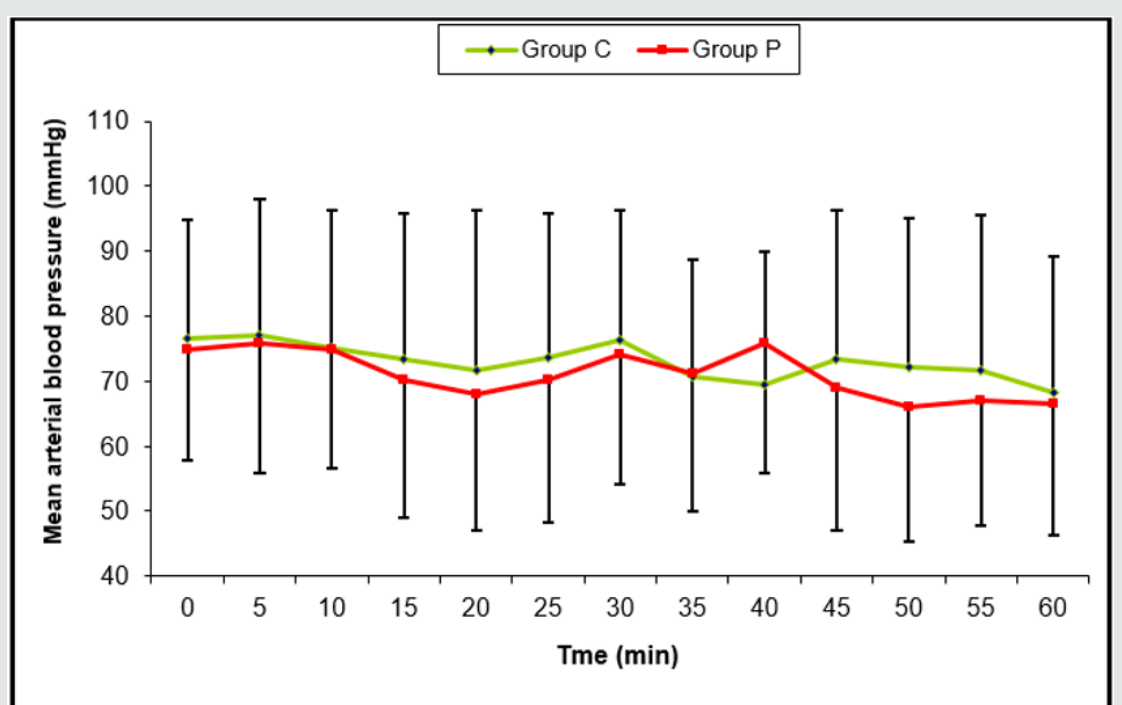

Figure 4: Intra-operative mean arterial blood pressure $(\mathrm{mmHg})$ of the two studied groups.

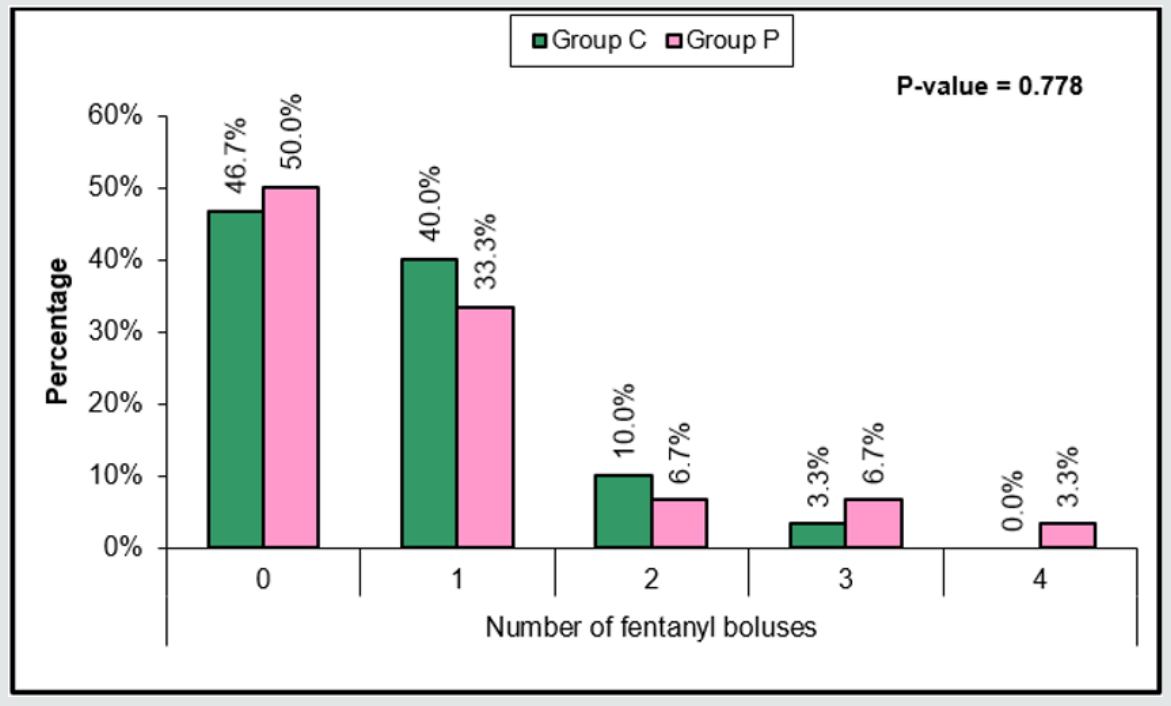

Figure 5: Comparison between the two studied groups regarding number of fentanyl boluses requirement intra-operative.

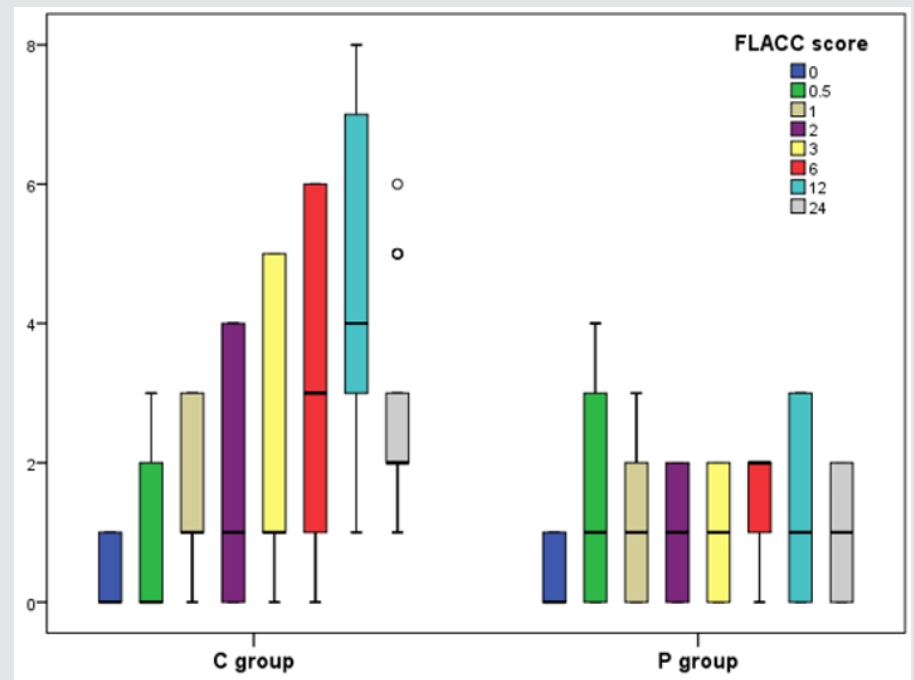

Figure 6: Postoperative FLACC scoring level of the two studied groups. 


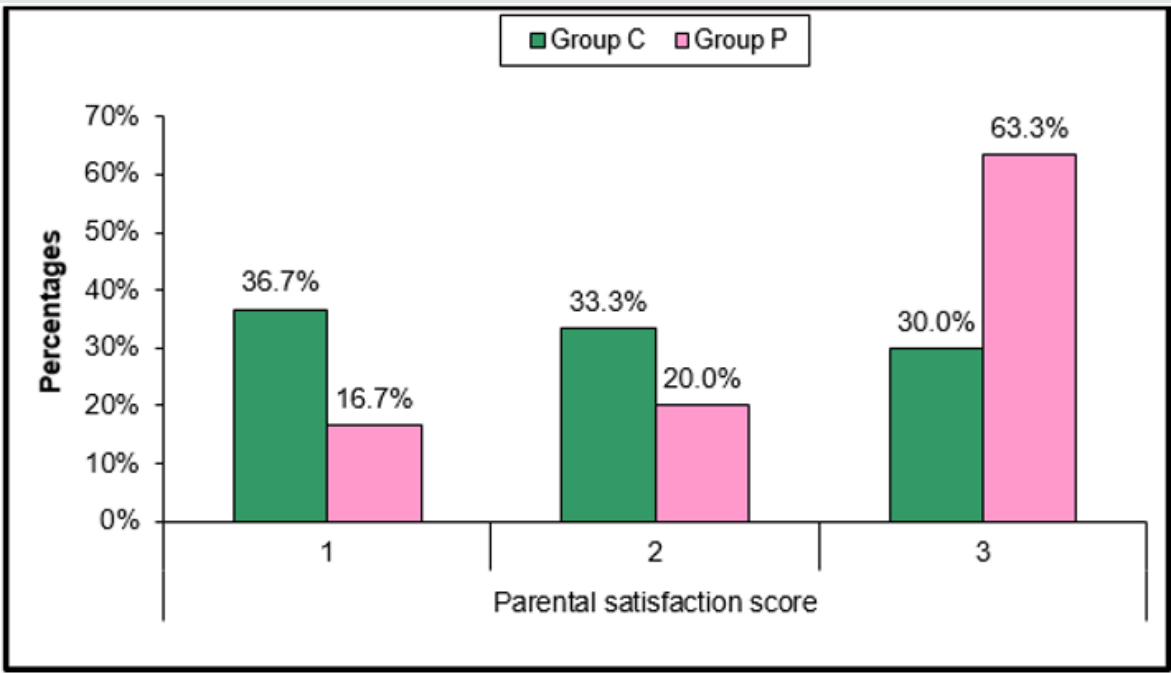

Figure 7: Parental satisfaction scoring among research groups.

Table 2: Intra-operative heart rate (beat/min) of the two studied groups ( $\bullet$ : Independent $\mathrm{t}$-test).

\begin{tabular}{|c|c|c|c|c|c|}
\hline Heart Rate (Beat/Min) & Group C No. $=30$ & Group P No. $=30$ & Test Value & P-Value & Sig \\
\hline $0 \mathrm{~min}$ & $106.67 \pm 14.88$ & $104.37 \pm 12.54$ & 0.647 & 0.52 & NS \\
\hline $5 \mathrm{~min}$ & $107.35 \pm 17.39$ & $105.29 \pm 15.32$ & 0.487 & 0.628 & NS \\
\hline $10 \mathrm{~min}$ & $105.42 \pm 17.60$ & $104.42 \pm 13.65$ & 0.246 & 0.807 & NS \\
\hline $15 \min$ & $103.66 \pm 18.92$ & $99.74 \pm 16.58$ & 0.853 & 0.397 & NS \\
\hline $20 \min$ & $101.78 \pm 21.30$ & $97.64 \pm 16.60$ & 0.84 & 0.405 & NS \\
\hline $25 \min$ & $103.94 \pm 18.64$ & $99.83 \pm 17.56$ & 0.879 & 0.383 & NS \\
\hline $30 \mathrm{~min}$ & $106.45 \pm 16.54$ & $103.61 \pm 15.47$ & 0.687 & 0.495 & NS \\
\hline $35 \min$ & $100.82 \pm 14.56$ & $100.76 \pm 16.79$ & 0.015 & 0.988 & NS \\
\hline $40 \mathrm{~min}$ & $99.76 \pm 16.87$ & $105.45 \pm 15.64$ & 1.335 & 0.181 & NS \\
\hline $45 \min$ & $103.47 \pm 19.50$ & $98.43 \pm 17.31$ & 1.058 & 0.294 & NS \\
\hline $50 \min$ & $102.42 \pm 19.44$ & $95.64 \pm 16.21$ & 1.467 & 0.148 & NS \\
\hline $55 \mathrm{~min}$ & $101.76 \pm 20.45$ & $96.45 \pm 14.68$ & 1.155 & 0.253 & NS \\
\hline $60 \mathrm{~min}$ & $98.40 \pm 17.60$ & $95.95 \pm 15.51$ & 0.572 & 0.569 & NS \\
\hline
\end{tabular}

Table 3: Intra-operative mean arterial blood pressure $(\mathrm{mmHg})$ of the two studied groups, $(\bullet$ : Independent $\mathrm{t}$-test).

\begin{tabular}{|c|c|c|c|c|c|}
\hline MABP (mmHg) & Group C No. $=30$ & Group P No. $=30$ & Test value & P-value & Sig \\
\hline $0 \mathrm{~min}$ & $76.46 \pm 18.33$ & $74.83 \pm 17.06$ & 0.357 & 0.723 & NS \\
\hline $5 \mathrm{~min}$ & $77.14 \pm 20.84$ & $75.75 \pm 19.84$ & 0.265 & 0.792 & NS \\
\hline $10 \min$ & $75.21 \pm 21.05$ & $74.88 \pm 18.17$ & 0.065 & 0.948 & NS \\
\hline $15 \mathrm{~min}$ & $73.45 \pm 22.37$ & $70.20 \pm 21.10$ & 0.579 & 0.565 & NS \\
\hline $20 \mathrm{~min}$ & $71.57 \pm 24.75$ & $68.10 \pm 21.12$ & 0.584 & 0.561 & NS \\
\hline $25 \mathrm{~min}$ & $73.73 \pm 22.09$ & $70.29 \pm 22.08$ & 0.603 & 0.549 & NS \\
\hline $30 \mathrm{~min}$ & $76.24 \pm 19.99$ & $74.07 \pm 19.99$ & 0.42 & 0.576 & NS \\
\hline $35 \mathrm{~min}$ & $70.61 \pm 18.01$ & $71.22 \pm 21.31$ & 0.12 & 0.905 & NS \\
\hline $40 \mathrm{~min}$ & $69.55 \pm 20.32$ & $75.91 \pm 20.16$ & 1.217 & 0.229 & NS \\
\hline $45 \mathrm{~min}$ & $73.26 \pm 22.95$ & $68.89 \pm 21.83$ & 0.756 & 0.453 & NS \\
\hline $50 \mathrm{~min}$ & $72.21 \pm 22.89$ & $66.10 \pm 20.73$ & 1.084 & 0.283 & NS \\
\hline $55 \mathrm{~min}$ & $71.55 \pm 23.90$ & $66.91 \pm 19.20$ & 0.829 & 0.411 & NS \\
\hline $60 \mathrm{~min}$ & $68.19 \pm 21.05$ & $66.41 \pm 20.03$ & 0.336 & 0.738 & NS \\
\hline
\end{tabular}

Citation: Sabri A Soltan, Hesham S Abdelraouf, Mahmoud M Alsagheir. Ultra-Sound Guided Caudal Epidural Blockade Analgesia in 
Table 4: Comparison between the two studied groups regarding number of fentanyl boluses requirement intra-operative.

\begin{tabular}{|c|c|c|}
\hline Number of Fentanyl Boluses & Group C No. $=\mathbf{3 0}$ & Group P No. $=\mathbf{3 0}$ \\
\hline 0 & $14(46.7 \%)$ & $15(50.0 \%)$ \\
\hline 1 & $12(40.0 \%)$ & $2(33.3 \%)$ \\
\hline 2 & $3(10.0 \%)$ & $2(6.7 \%)$ \\
\hline 3 & $1(3.3 \%)$ & $1(3.3 \%)$ \\
\hline 4 & $0(0.0 \%)$ & 1.439 \\
\hline Fisher exact test & & $0.778(\mathrm{NS})$ \\
\hline P-value & \multicolumn{2}{|c|}{} \\
\hline
\end{tabular}

Table 5: Postoperative FLACC scoring level of the two studied groups (•: Mann-Whitney test).

\begin{tabular}{|c|c|c|c|c|c|}
\hline FLACC Score & Group C No. $=\mathbf{3 0}$ & Group P No. $=\mathbf{3 0}$ & Test value & P-value & Sig \\
\hline 0 & $0(0-1)$ & $0(0-1)$ & -0.517 & 0.605 & NS \\
\hline 0.5 & $0(0-2)$ & $1(0-3)$ & -1.304 & 0.192 & NS \\
\hline 1 & $1(1-3)$ & $1(0-2)$ & -1.773 & 0.13 & NS \\
\hline 2 & $1(0-4)$ & $1(0-2)$ & -1.513 & 0.031 & NS \\
\hline 3 & $1(1-5)$ & $10-2)$ & -2.158 & 0.002 & HS \\
\hline 6 & $3(1-6)$ & $2(1-2)$ & -3.15 & 0 & HS \\
\hline 12 & $4(3-7)$ & $1(0-3)$ & -5.54 & -4.795 & \\
\hline
\end{tabular}

Table 6: Parental satisfaction scoring among research groups.

\begin{tabular}{|c|c|c|c|c|c|c|c|}
\hline \multirow{2}{*}{ Parental satisfaction score } & \multicolumn{2}{|c|}{ Group C } & \multicolumn{2}{|c|}{ Group P } & \multicolumn{3}{c|}{ Chi-square test } \\
\cline { 2 - 8 } & No. & \% & No. & \% & X2 & P-value & Sig. \\
\hline 1 & 11 & $36.70 \%$ & 5 & $16.70 \%$ & 6.821 & 0.033 & S \\
\hline 2 & 10 & $33.30 \%$ & 6 & $20.00 \%$ & & \\
\hline 3 & 9 & $30.00 \%$ & 19 & $63.30 \%$ & & & \\
\hline
\end{tabular}

\section{Discussion}

Caudal blockade is a routine anesthetic practice in many centers all over the globe aiding in providence of adequate post-operative analgesia on the other hand paravertebral blockage as a mode of postoperative pain management protocol among pediatric cases is implemented occasionally, in particular by anesthesiologists Well trained and experienced in usage of sonographic -guided blocks since it carries risks for complications if not professionally conducted particularly pneumothorax $[13,14]$. A prior research study like the current study in approach and methodology revealed and displayed among the research study results that administering single-shot paravertebral Blockage resulted in enhanced levels of analgesia than caudal blockage in pediatric group of cases consequently after conducting pyeloplasty. Surgical intervention in which 15 of the 24 study subjects in paravertebral research group didn't require rescue analgesia administration [14,15]. Furthermore, another research team of investigators have conducted a prior Pilot observational research study among 24 c pediatric research study subjects having a major renal surgical intervention in which they have observed among their study findings that, the median postoperative analgesic duration accomplished using administration of a single paravertebral blockage shot have been around 10 hours [16-18].
Similar research study findings were observed and revealed from prior studies in which the investigators compared and contrasted in a retrospective manner continuous thoracic paravertebral blockade to continuous lumbar epidural mode of 1 blockage coming to the conclusion that analgesia levels accomplished paravertebral blockage was statistically significantly higher, $p$ value $<0.05$ ) than cases observed in the lumbar epidural research group $[1,5,9]$. Prior investigators have interestingly justified the longer analgesia conductance period using paravertebral blockade in comparison and contrast to caudal mode of blockade is possibly due to the enhanced epidural space vascularity causing elevated systemic local anesthetic agent absorption patterns and therefore briefer time period of performing epidural analgesia $[3,8,10]$.

Another research group of investigators have interestingly mentioned that time taken for rescue analgesic requirement after sonographic -guided paravertebral blockage among cases aged around 2-10 years old having surgical thoracotomy procedure is around 8 to 10 hours in above $80 \%$ of cases denoting enough analgesia duration postoperatively. [4,15]. A prior group of investigators have revealed among their research study findings that the side effects incidence is greater using caudal blockage technique in comparison to when compared to non-caudal forms of regional analgesia techniques $[11,14]$. Prior research studies 
have in an interesting manner shown that caudal Blockage is more effective than ilioinguinal/ iliohypogastric nerve blocks within the early postoperative follow up period as regards pain management $[2,14]$.

\section{Conclusion and Recommendation}

Our research team in the current study have concluded that analgesia after Sonographic-guided paravertebral blockage administering bupivacaine is superior in analgesic effects in comparison and contrast to sonographic guided mode of caudal epidural blockage, however in order to verify the current research study findings it is better to perform future research studies in a multicentric manner with larger sample sizes taking in consideration the anatomic challenges such as spinal deformities.

\section{References}

1. El-Fawy DM, El-Gendy HA (2014) Ultrasound-guided transversus abdominis plane block versus caudal block for postoperative pain relie in infants and children undergoing surgical pyeloplasty. Ain-Shams J Anesthesiol 7(2): 177-81.

2. Tug R, Ozcengiz D, Güneş Y (2011) Single level paravertebral versus caudal block in paediatric inguinal surgery. Anaesth Intensive Care 39(5): 909-913.

3. Chalam KS, Patnaik SS, Sunil C, Bansal T (2015) Comparative study of ultrasound-guided paravertebral block with ropivacaine versus bupivacaine for post-operative pain relief in children undergoing thoracotomy for patent ductus arteriosus ligationsurgery. Indian J Anaesth 59(8): 493-498.

4. Moawad HE, Mousa SA, El-Hefnawy AS (2013) Single-dose paravertebral blockade versus epidural blockade for pain relief after open renal surgery: a prospective randomized study. Saudi J Anaesth 7(1): 61-67.

5. Shanthanna H, Singh B, Guyatt G (2014) A systematic review and metaanalysis of caudal block as compared to noncaudal regional techniques for inguinal surgeries in children. Biomed Res Int 17: 890626

6. Bengisun ZK, Ekmekci P, Haliloglu AH (2012) Levobupivacaine for postoperative pain management in circumcision: caudal blocks or dorsal penile nerve block. J Turk Soc Algology 24(4): 180-186.
7. Splinter WM, Thomson ME (2010) Somatic paravertebral block decreases opioid requirements in children undergoing appendectomy. Can J Anesth J Can Anesth 57(3): 206-210.

8. Gan TJ (2017) Poorly controlled postoperative pain: prevalence, consequences, and prevention. J Pain Res 10: 2287-2298.

9. Krane EJ, Weisman SJ, Walco GA (2018) The National Opioid Epidemic and the Risk of Outpatient Opioids in Children. Pediatrics 142(2): e20181623.

10. Liu C, Ulualp SO (2015) Outcomes of an Alternating Ibuprofen and Acetaminophen Regimen for Pain Relief After Tonsillectomy in Children. Ann Otol Rhinol Laryngol 124(10): 777-781.

11. Sheng Chin Kao and Chia Shiang Lin Caudal (2017) Epidural Block: An Updated Review of Anatomy and Techniques Biomed Res Int 5: 9217145.

12. Tighe SQM, Michelle DG, Nirmal Rajadurai (2010) Paravertebral block Continuing Education in Anaesthesia Critical Care \& Pain 10 (5): 133137.

13. McNicol ED, Rowe E, Cooper TE (2018) Ketorolac for postoperative pain in children. Cochrane Database Syst Rev 7: CD012294.

14. Harbaugh CM, Lee JS, Hu HM, McCabe SE, Voepel LT et al. (2018) Persistent opioid use among pediatric patients after surgery. Pediatrics 141(1): e20172439.

15. Shah RD, Suresh S (2017) Acute pain management in the pediatric ambulatory setting: How do we optimize the child's postoperative experience? J Clin Anesth 40: 103-104.

16. Van Cleve WC, Grigg EB (2017) Variability in opioid prescribing for children undergoing ambulatory surgery in the United States. J Clin Anesth 41: 16-20.

17. Joshi G, Gandhi K, Shah N, Gadsden J, Corman SL (2016) Peripheral nerve blocks in the management of postoperative pain: challenges and opportunities. J Clin Anesth 35: 524-529.

18. Shah RD, Suresh S (2013) Applications of regional anaesthesia in paediatrics. Br J Anaesth 111(Suppl 1): i114-i124.

19. Johr M (2015) Regional anaesthesia in neonates, infants and children: an educational review. Eur J Anaesthesiol 32(5): 289-297.

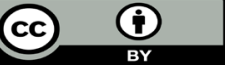

This work is licensed under Creative Commons Attribution 4.0 License

To Submit Your Article Click Here: Submit Article

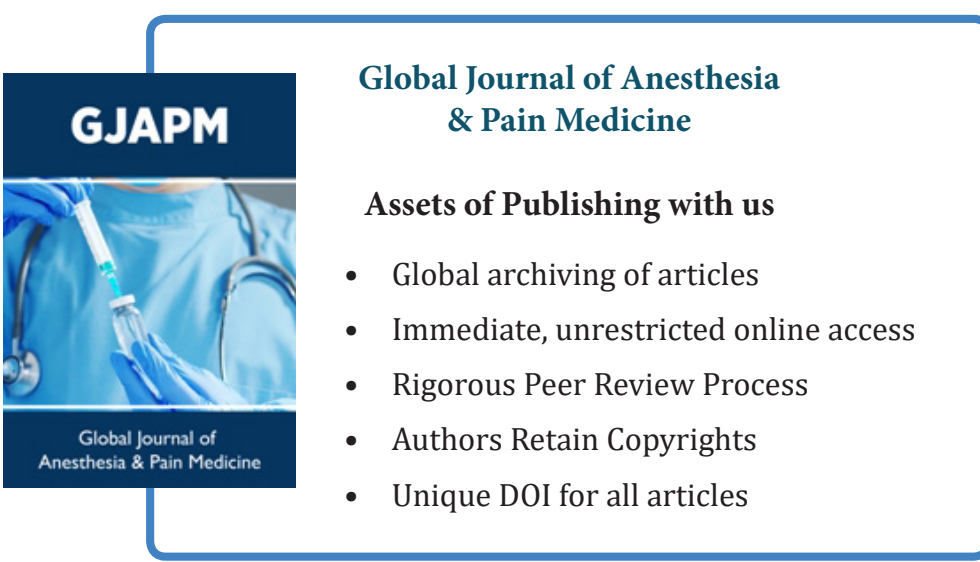

